\title{
The Columbus Linguistics in High School experience: Fits and starts as a prelude to success
}

\author{
Victora Paxton, Carly Dickerson \& Brian D. Joseph*
}

\begin{abstract}
We report here on our efforts to incorporate linguistics into the high school curriculum in a large midwestern metropolitan area through a universitybased initiative — Linguistics in High School (LxHS) — spearheaded by the Department of Linguistics at The Ohio State University. We offer a brief history of the project, and explain our strategy of targeting non-public schools and the practical nature of the reasoning behind this decision. We chronicle the ups and downs of our efforts, ultimately reporting on our success with implementing a linguistics course and a linguistics club at a small local STEM-oriented high school. This partnership between the school and the Linguistics Department has allowed, among other things, for on-site visits by the students to phonetics and sociolinguistics labs. By presenting our challenges, strategies, failures, and successes, we hope that others may be encouraged to evaluate how they can make a difference in their locale and with the resources they have.
\end{abstract}

Keywords. linguistic pedagogy; high school linguistics; AP Linguistics

1. Introduction. It is universally agreed in the linguistics community that knowledge of linguistics among the general American public is negligible, and this includes the average American high school student. While students are exposed to English grammar and to foreign languages, the discoveries of language scientists and especially the methods of linguistic analysis are generally absent from the typical high school curriculum. Overcoming this gap is essential to developing an informed public that is sensitive to the important role that language plays in our collective and individual lives.

Members of the Linguistic Society of America (LSA) may well wonder what it would take to address this issue in their own community and what challenges they might face. By way of addressing such concerns and encouraging action on the part of LSA members and other interested parties, we detail here our efforts to incorporate linguistics into the high school curriculum in Columbus, Ohio through the Ohio State University Linguistics in High School (OSU LxHS) initiative.

We start with a brief history of the project, including our initial goals and struggles. We then explain our strategy of targeting non-public schools and our reasoning behind this decision. We chronicle the ups and downs of our efforts, but finally, we turn to our success at a small local alternative high school, where we are currently offering an elective course in linguistics. We then give an assessment of the actual course that was taught, and ultimately discuss the benefits that have come from this joint enterprise as well as our trajectory for the future. Throughout each section our emphasis is on the value of a partnership between those within and those outside of The Ohio State University; indeed, presenting the initiative as a joint experiment between a

\footnotetext{
* We happily acknowledge the financial support of the Ohio State University Office of Outreach and Engagement, the Ohio State University Global Arts + Humanities Discovery Theme, and the Ohio State University Department of Linguistics, as well as the enthusiasm and logistical support of various administrators at the Metro Early College High School. Authors: Victora Paxton, The Ohio State University, B.A. 2020 (victorapaxton@gmail.com), Carly Dickerson, The Ohio State University, Ph.D. 2021 (dickerson.253@osu.edu), \& Brian D. Joseph, The Ohio State University (joseph.1@osu.edu).
} 
university or college unit and the local school is a strong selling point. We also document the need for persistence over the course of our efforts and for "thinking locally". By presenting our challenges, strategies, failures, and successes, our hope is that others may be encouraged to evaluate how they can make a difference in their locale and with the resources they have available to them.

2. A brief history of the project. Every year at The Ohio State University (OSU), the Department of Linguistics hosts a Linguistics Pedagogy Lecture in which a linguist noted for teaching excellence and innovation is invited to give a lecture to the department on a matter of relevance to our pedagogical and instructional goals and mission. In 2018, the lecture was given by Dr. Richard Larson, Stony Brook University, who is the chair of the LSA's AP Linguistics Committee. He talked about the benefits of educating high school students in linguistics as well as the goals of the AP Linguistics Initiative. In attendance was then-undergraduate student, Victora Paxton, who was inspired by Dr. Larson's lecture. Not long after, they sought out Brian Joseph, the OSU faculty member who had been involved in organizing the lecture, and met with him to discuss how they could put Dr. Larson's ideas into practice locally and expose more Central Ohio high school students to linguistics within their own classrooms. ${ }^{1}$ Regular meetings between the two continued throughout the 2018-2019 academic year to strategize about how to do this, and thus was born the Linguistics in High School (LxHS) initiative at OSU.

During the first few months, Paxton and Joseph focused their efforts on familiarizing themselves with the secondary education system in Ohio, taking stock of what resources were available, from personal contacts to pop-linguistics media online, and brainstorming as to what the LxHS initiative could offer to schools and their students. After that, they decided that offering a variety of progressively more involved kinds of partnerships, namely an assemblystyle presentation, a linguistics club at the school, and finally an introduction to linguistics course, would be a manageable yet ambitious goal. Additionally, they came to learn that nonpublic schools had more flexibility not only in course-offerings but in teaching personnel as well. Targeting non-public schools would make the goal of doing a linguistics course more likely because a graduate student from the OSU Linguistics Department, who would be comfortable with introductory linguistics content as opposed to a typical high school teacher, without particular training in linguistics, could teach without having a teaching license.

In the spring of 2019, they sent out a letter of invitation to 25 private schools in the area, asking to meet with administrators in order to discuss the possibility of building a partnership between the school and the LxHS team. Two of the schools responded to the letter, and after initial meetings with administrators at the two schools, the LxHS team did an assembly presentation to the full student body (some 100 students in all) at one of the schools as a way of showing what linguistics could offer. The team included Dr. Julie McGory of the Linguistics Department, who serves as the undergraduate major advisor and director of the department's Summer Linguistics Institute for Youth Scholars, ${ }^{2}$ and two graduate students, Zack Jones and Daniel Puthawala, and the assembly consisted of five short "vignettes" explaining different aspects of the field (e.g., writing systems, variation, computers and linguistics, etc.). The

\footnotetext{
${ }^{1}$ Paxton theirself was a graduate of Reynoldsburg High School in a Columbus suburb and thus to some extent had an insider's perspective on the local high school scene.

${ }^{2}$ SLIYS is a multi-week summer enrichment experience for high school students that was developed some ten years ago by the OSU Department of Linguistics and is held each summer now. For details and further information about this way of bringing linguistics to high-schoolers, see https://linguistics.osu.edu/undergrad/sliys.
} 
assembly was a great success, with the students clearly engaged in and enjoying the presentations, so that things appeared hopeful; however, over the subsequent summer, due to funding problems, the school unfortunately shut down entirely. Thus, the search for a school partnership continued.

In Autumn of 2019, Paxton and Joseph reached out to a single public school based on the recommendation of McGory: Metro Early College High School, a STEM-oriented school located on the far west edge of the OSU campus. Metro is an officially recognized (by the Ohio General Assembly and Ohio Department of Education) "Community STEM" School, that was originally a joint effort between OSU and Battelle Memorial Institute (a large private research institute and think tank in Columbus). Now it is a publicly funded gateway school to OSU, with students able to take college courses as early as sophomore year.

The Metro staff responded quickly to us, leading to the partnership the LxHS team has with the Metro School today. The enthusiasm and the receptivity of the Metro administration (especially Dean Cory Neugebauer) and faculty were crucial.

Thus, it ensued that in the spring semester of 2020, the first Introduction to Linguistics course was co-taught to Metro students by OSU Linguistics graduate student Carly Dickerson, and the foreign language teacher at the school, Angy Bernthold, who served as the teacher of record for the class to satisfy state requirements. Dickerson taught two days a week and Bernthold covered the remaining days, primarily giving the students encouragement and assistance as they carried out tasks related to work and the project that Dickerson had assigned, and as they watched and reacted to online linguistics documentaries and the like. In addition to the class, a student-led Linguistics Club was instituted as well. Due to the pandemic, the class was transitioned to an entirely online format in March 2020, halfway through the semester, and club meetings were cancelled for the remainder of the term, but this partnership is still active and both parties are working together to determine the best course of action for continuing the availability of linguistics for Metro students.

There was an issue with compensation for Dickerson's teaching that is worth making known, as it shows another potential area for missteps for anyone pursuing an initiative like OSU LxHS. Initially, we were under the impression that the Metro School would pay her, but they thought that we would pay! ${ }^{3}$ Since we wanted to proceed with the course, we undertook to find some funding for her efforts. We eventually were able to cobble together some money in the form of an enhanced travel/ research grant from the Linguistics Department - funding that was especially valuable as Dickerson was facing research expenses associated with her dissertation - and small grants from other OSU-internal sources, e.g. the Office of Outreach and Engagement and the Global Arts and Humanities Discovery Theme, that we applied for throughout the year.

It turned out that in the academic year 2020-2021, due to planning uncertainties and more pressing administrative concerns occasioned by the pandemic, it was not possible to continue the linguistics course at the Metro School; however, the Linguistics Club was reinstated so that linguistics in some form was maintained at the school in 2020-2021.

\footnotetext{
${ }^{3}$ The misunderstanding may have been based on the linguistically interesting ambiguity of the verb provide. In our early meetings and discussions with the Metro School, we talked about our being able to "provide" an instructor, by which we meant that we had people with the expertise and knowledge to teach the class but which the Metro School, quite reasonably, took to mean that we would undertake, i.e. "provide", the compensation as well for that person's expertise and time in the classroom.
} 
Our hope was that once it would become possible to return to a more normal situation budgetarily - the pandemic having made budgetary planning for the Metro School a particularly fraught exercise - there would be a good chance that the Metro School will want to reinstate linguistics classes as a regularly budgeted-for item in their curriculum. We are pleased to be able to report that as of June 2021, that is exactly what has happened, and as a result, the Metro School will be paying a local linguist to teach an introductory linguistics class at the high school, with full responsibility for the class five days a week. And, the club will continue as well. We count these developments as a huge success.

3. The course itself. The course was taken by 18 students, spanning grades 9 through 12 . All of them grew up in the Columbus area, but with rather diverse family languages, specifically Arabic, Bengali, Dutch, English, Japanese, Somali, Spanish; this diversity is reflective of Columbus's population. More than half of the students spoke $2+$ languages on a daily basis. Some students said they chose this course because of an interest in language, while others were placed into it by administrators. The students themselves had a broad range of talents, motivations, and interests, and constituted a fine group to teach linguistics to.

As perhaps with any successful course, a key to making the Metro course a success in the classroom was finding a way to capitalize on student strengths. To that end, Dickerson instituted a language description project in which native speakers of a language other than English were paired up with monolingual English speakers. This project allowed for elicitation exercises involving sound systems, core vocabulary, sentence patterns, and the like. Moreover, students were able to use the OSU Linguistics Department sound booths to do recordings and were taught how to analyze the sounds in Praat.

This approach also meant that multilingualism was presented as the norm, and that what might be (erroneously) considered to be a linguistic "deficiency" (e.g. as far as English was concerned) was actually a special kind of linguistic knowledge. Multilingual students were thus encouraged to share this knowledge with their monolingual peers in the classroom.

Without wanting to overstate outcomes, nonetheless, we feel that through this extended exercise, students learned about some of the practical benefits of knowing linguistics. For instance, they became able to educate others on how to pronounce their names, to explain details about English more effectively to older relatives, and to understand how to more effectively approach foreign-language learning. We were particularly pleased that some students said that linguistics was their favorite class. ${ }^{4}$

4. Linguistics club at Metro. As noted in section 2, besides the class itself, a linguistics club was started, taking advantage of Metro School's requirement that all students take part in some club activities. One hour a week is set aside in the school's schedule for such club participation. In the winter of 2020, January into March, before the pandemic hit, we were successful in having four meetings, led by Paxton but with the involvement as well of several undergraduate linguistics students - Katriese DeLeon, Andrew Duffy, Daniel Hughes, Matt Kincaid, Kenna Miller, and Julian Robbins - who were part of the Linguistics Department's undergraduate linguistics club, a group known as the UnderLings. These students made this Metro School club possible, spending hours in preparation and club meetings. Club activities ranged from watching language-related videos students found throughout the week to discussing linguistics research

\footnotetext{
${ }^{4}$ Fuller details on the syllabus and the assignments are available upon request.
} 
discoveries, covering such topics as phonetics and phonology, constructed languages, language and music, and writing systems.

The Linguistics Club represented a relatively cost-free means of keeping linguistics in the Metro School in some form and thus was particularly important during the academic year 20202021 when no course could be offered. The only difference in this second instantiation of the club was that Dickerson, inasmuch as there was no course for her to teach, instead supervised the UnderLings participants (Samuel Green, Xander Hall, Kate Kinnaird, Julia Redmond, and Katie Timmer) and acted as liaison with the school, drawing on her familiarity with the school from her time teaching the course the previous spring (2020). For this work, she was paid through a grant from the OSU Global Arts + Humanities Discovery Theme. The plan is for the club to continue in the current academic year (2021-2022) along with the course.

5. Conclusion. We realize that we may just have been lucky in the way that our various fits and starts ultimately led to success in developing a good working relationship with a local school and in bringing linguistics into its curriculum. However, in the hopes that our experience can be useful to others, we can summarize what we have learned as follows: ${ }^{5}$

- Those in the schools who are in control of the curriculum, such as principals and deans, tend to be impressed by the range of disciplines - covering both STEM and the Humanities and Social Sciences - that linguistics touches on.

- Perseverance and flexibility are needed (as with any "sales pitch!").

- One needs a willingness to "go with the flow" and take advantage of possibilities (since chance elements can be expected to come into play).

- The personal touch matters (the good rapport we established with Metro administration seems to have helped).

We close with the observation that carrying out the OSU LxHS initiative has been a challenge, but it has been one that was well worth taking on. We are encouraged by all that has happened with it, and look forward to the day when linguistics will be as much an ordinary and unremarkable part of the curriculum in our high schools as mathematics or history is today.

${ }^{5}$ A detailed report on the LxHS initiative was filed with the OSU Office of Outreach and Engagement in the fall of 2020; it can be accessed on the LxHS website (http://u.osu.edu/LxHS), where eventually other related materials will be posted as well. 